to Lachnocladium emend. Corner ; but it is Lentaria surculus (B.) Corner [= Lachnocladium compressum (B.) Lév.]; and the genus Lentaria contains only four of the 113 specific names of Lachnocladium, two referring to north temperate species. But what, or where, the Guinea and Bourbon collections of $L$. furcellatum may be is not known, and no mycologist would now assume their identity with the Brazilian merely because the pocket-lens had put them together 120 years ago.

Thus, by reference to 'literature' only, and by putting the cart before the horse, nomenclaturists have advocated as the lectotype of this important tropical genus a species which cannot yet be resolved, which may never be resolved, which may be a mixture of more than one genus, or, if uniform, which represents only 4 per cent of the genus : and this part is not characteristically tropical as the original diagnosis implied. In detail, we do not know whether Lentaria is to become a synonym of Lachnocladium, in which case Stelligera Heim ex Doty takes the place of Lachnocladium emend. Corner, or my classification, based on a world monograph, is to be upheld : about fifty species, several of them common, are affected. But, further, if Lachnocladium should take over from Lentaria, then Lachnocladium may easily become a synonym of Ramaria or take the place of Clavariella, for Lentaria is not nearly so clear-cut a genus as Lachnocladium emend. Corner. If Ramaria should take over Lachnocladium, this well-known name of long standing (a hundred years) for tropical species will disappear ; if Lachnocladium should take over from Clavariella, then the names of a hundred more species of temperate and tropical countries will have to be changed, and some of these are the best known of all clavarias. Such doubts, problems and consequences should have been resolved by research into the organisms themselves before the lectotype was proposed, as I did in my monograph before I emended Lachnocladium by carefully considering its relations with all other species of the family: no such absurdity as this can enter into my classification. Yet, this blind man's buff, as is the procedure of which I complain, passes as scientific nomenclatorial procedure and may, by reason only of priority, as in this instance, nullify fundamental research, which research would then be used for further nomenclatorial juggling with generic names. The procedure is not merely detrimental to mycology but also contrary to scientific thought, which must exact stability of nomenclature from taxonomy.

The second example is the choice of $P$. quisquiliaris as lectotype of Pistillaria, again without monographic revision. My researches showed that the effect of this lectotype was to merge the two large foundation-genera Pistillaria and I yphula into one and to place a later name, Cnazonaria, that has never been current, where Pistillaria can readily be maintained, as I have done in my monograph in accordance with Recommendation VI, Art. 18, of the International Rules of Nomenclature $(6,98,99)$. Thus, this blind man's buff may also bowl over foundationgenera.

For the sake of scientific research, for mycology, and for botany, which demand stability of nomenclature, I propose to international taxonomists the following principles:

(1) That typification of genera by lectotypes implies generic emendation, which in turn implies revision of the genus and its allies so that the full consequence of the proposed lectotype can be seen;
(2) that any such typification without the necessary revision should be rejected.

The proposal is an amplification of paragraph 4 of Appendix 1 to the International Rules of Botanical Nomenclature, as adopted at the seventh International Botanical Congress?. It emphasizes what is so often overlooked, especially in connexion with lower plants, that many of the nomenclatorial problems are caused by lack of knowledge of the organisms, which no amount of static typification will improve. In the case of Basidiomycetes, such revision means full hyphal analysis, as explained in the introduction to my monograph, the absence of this analysis being the main source of errors of present-day classifications, whether concerned with lectotypes or not. Thus, if my proposal is adopted, the making of lectotypes will be the outcome of fundamental research, slow but sure, in accordance with the great importance attached to the concept of the generic type. If the proposal is not adopted, there will be so many more of the confusions that $I$ have instanced that many current generic names will become unserviceable in a multiplicity of interpretations, while others will be lost and unfamiliar ones put in their stead.

[Nov. 10.

${ }^{1}$ Clements, F. E., and Shear, C. Is., "The Genera of Fungl" (1931).

Donk, M. A., Bull. Bot. Gdn. Buit., Ser. III, 17, 155 (1941); VII Int. Bot. Congr. Special Committee for Fungi, 1 (1950).

${ }^{3}$ Doty, M. S., Lloydia, 13, 1 (1950).

- Rogers, D. P., Farlowia, 3, 425 (1949) ; 4, 15 (1950).

- Singer, R., Mycologia, 36, 65 (1944).

- Corner, E. J. H., Ann. Bot. Mem., 1 (1950); Nature, 168, 620 (1950). Stevenson, J. A., and Rogers, D. P., The Plant Disease Rep., 34, $332(1950)$.

\section{ACCIDENT PRONENESS}

$\mathrm{TN}$ a contribution to the eleventh issue of "New Biology"* Dr. R. MacKeith suggests that the idea or hypothesis of accident proneness may turn out to be as important for saving lives as sulphonamides and the antibioties like penicillin have been.

In Britain there are 1,000 fatal and 350,000 other accidents a year in factories; 5,000 deaths from accidents in the home, and 3,000 deaths and 250,000 injuries on the roads. This can be examined from various aspects. The medical care is expensive. It is wasteful of labour that might be productive. $I_{v}$ is the cause of suffering to those bereaved, to the surviving injured and especially to those who are mutilated and scarred. That such a high accident-rate is tolerated appears to indicate that the benefits of having buses, motor-cars and lorries are worth more than are several thousand lives and a quarter of a million injuries a year. Can these accidents be prevented ?

In 1919, Greenwood and Woods, working for the Industrial Fatigue Research Board, observed that in a group of workers studied over a period, accidents did not occur uniformly throughout the group; some of the workers had repeated accidents, so that 80 per cent of the accidents happened to 20 per cent of the workers. This ratio has been confirmed by a number of studies of industrial accidents and of road accidents. Such an uneven distribution might arise from a simple chance distribution; but that is not an adequate explanation of the repeated observations. It might be because having one accident makes a

* New Biology, 11. Edited by M. L. Johnson and Michael Abercrombie. Pp. $123+16$ plates. (Harmondsworth: Penguin Books, 


\section{Nc. 4285 December 15, 1951 N A T U R E}

person liable to suffer further accidents, or it might be because individuals differ in their liability to accident, even with the same degree of risk.

Thus, in children, the peak age for road accidents is four to six years; children of this age-group have special characteristics, physical, mental and emotional, and these may be responsible for the high accident-rate. Children are active, progressing usually by running rather than walking, and just acquiring the grace in movement which implies full control. They may see a motor-car thirty yards away and not appreciate that it is moving rapidly towards them. They believe that grown-ups are all-powerful and so they may well believe the car could be stopped if necessary. These small children are impulsive and act suddenly and may be moved to action by fantasies or strongly felt emotions. In brief, their high accidentrate may be from their relative physical, intellectual or emotional defects compared with the children of 7-9 who have fewer accidents.

The same possibilities arise when accident-prone adults are studied. An American insurance company's analysis of a series of industrial accidents suggested that "mechanical hazards caused less than 9 per cent, physical and mental defects about 3 per cent, lack of skill less than 8 per cent", leaving personality defects to account for 80 per cent of the accidents.

The idea of accident proneness of psychological origin was first put forward by Farmer and Chambers in a Medical Research Council report published in 1926, and also by Marbe in the same year. Attempts were made to correlate accident proneness with the 'reaction time'. ('Reaction time' is the time between receiving a stimulus and acting upon this perception.) 'I'here is little correlation, and though there is a higher correlation with elaborate tests demanding a close co-ordination of stimulus and action, it was not high enough to justify selection of workers on such tests. In dealing with motor-car drivers it was found that failure to do certain psychological tests was reflected in a higher accident-rate. Farmer and Chambers also found that liability to accident is a stable character. istic. Bus drivers with a high number of accidents in their first year of work tended to go on having an excessive number. Inexperience in itself does give a rather increased rate of accidents ; but, after the first year, further experience does not reduce the accident-rate. These authors suggested that by taking the results of certain tests and the reports of the accident incidence in the first years of driving, some accident-prone drivers could be detected and perhaps diverted to other occupations.

In the United States Dr. Flanders Durban has made a special study of accident-prone patients, and her work showed that, first, most (80 per cent) of those who have had one serious accident tend to have others, and have a particular kind of personality. The other 20 per cent do. not tend to have more accidents and do not have special personality featurez. Secondly, people with a history of minor accidents are more likely to have serious accidents. If a group of fracture patients is compared with a group of patients with heart disease, 76 per cent of the total illness period in their previous medical history was the result of accidents for the fracture patients, and 2 per cent for the heart patients. Thirdly, accidentprone persons have unusually good health records; they have not been off work much and are especially free of colds and indigestion. Fourthly, they are not clumsy or dull; they are quick-minded "men of action not deliberation", but inarticulate about expressing their feelings. Fifthly, there are various types of accident-prone persons. The most usual type are happy-go-lucky, impulsive, casual people "who divorce and remarry easily". From the psychological point of view they are hostile to authority, but evade this feeling. That is, they are not openly hostile to parents or employers, but take up fatalistic 'don't care' attitudes towards others.

Accident-prone children have pent-up aggression and resentment which is shown by restlessness, stealing, lying or truancy. Fabian and Bender, studying children of 1-15 years with severe head injuries, found that 38 per cent of them had had previous major accidents, 83 per cent of the children had inadequate parents-sometimes heavy drinkers, sometimes a domineering, abusive father and an overprotective mother. These children are like delin. quents; but where one breaks laws, the other breaks bones. The guilty feelings of some of the fracture patients were revealed by remarks such as "It serves me right". Accidents appear to happen when children are doing forbidden things; and it is suggested that some children may be reckless in order to bring punishment upon themselves because they cannot bear the feelings they have of guilt.

Data about accidents in the home are difficult to get. One study suggested that two-thirds of these are due to carelessness of one sort or another. Accid. ents do happen to the tired and irritable, so that personal rather than structural factors are the main cause of accidents in the home. "But it is clear that there are most injuries where housewives live in overcrowded and ill-equipped homes; they are distracted by the difficulties of keeping an eye on the children while trying to get through the day's work without confusion and disorder. A long story of fighting against the heavy odds of environment often lies behind expressions such as thoughtlessness, carelessness or negligence."

Accident proneness certainly exists in some people. It is not the only factor in the causation of accidents. "Dangerous machines in factories still must be shielded; we must try to improve our roads, and make our homes safer. We must help children to learn safe behaviour. Does the idea of accident proneness offer us any further ways in which accidents might be reduced?"

A transport company transferred their drivers who had most accidents to other jobs and so reduced accidents to one-fifth of what they had been. The ex-drivers still suffered injuries, but only to themselves. Most of the fatal road accidents in Great Britain involve public-service vehicles such as buses and lorries, and so it should be possible to know the incidence of accidents, to recognize the accident-prone drivers and persuade them to change to other jobs. This is a field in which trade unions and employers should co-operate, for it may be difficult to work out how such a scheme is to be administered. More should be known about the tests devised for reaction time and the psychological tests which might be used. This would cost money, but not much in comparison with the immense sums proposed for road improvements "to make roads safer". It is unlikely that such expensive schemes will be possible for a long time, and "however much external conditions were improved, with a view to reducing the general accident rate, those specially prone would still have a higher accident rate under all conditions than those with a relatively low accident proneness". If legislation 
is to be introduced involving limitations on the liberty of the subject, the case for such limitations will have to be very strong before it is acceptable to Parliament.

These would be measures to deal with a situation that has arisen and has been discovered. On a longerterm policy the abnormal reaction to authority shown by the accident-prone should not arise. A child who has repeated accidents should be regarded as having a behaviour problem which needs treatment, and. the environment in which the accident-prone personality develops should be removed or altered.

\section{LONDON TO BIRMINGHAM TELEVISION LINK}

$\mathrm{A}^{\mathrm{T}}$

$\mathrm{T}$ a meeting of the Institution of Electrical Engineers on November 8, a paper entitled "The London-Birmingham Television-Cable System" was presented by T. Kilvington, F. J. M. Laver and H. Stanesby, members of the Post Office Engineering Department. This paper described the cable system which provides channels for relaying television signals simultaneously in both directions between the television broadcasting stations at Alexandra Palace and Sutton Coldfield. The corresponding radio link between these two stations was described in a paper read before the Institution last session under the title "The London-Birmingham Television RadioRelay Link", by R. J. Clayton, D. C. Espley, G. W. S. Griffith and J. M. C. Pinkham, of the Research Laboratories of the General Electric Co., Ltd., and since published in the Proceedings (98, Part 1).

The radio link provides a connexion between the Museum Telephone Exchange in London and Tele. phone House in Birmingham, with four intermediate repeater stations. Among the conditions of the overall electrical performance, specified by the Post Office, was the requirement that all terminal and repeater stations should work unattended. This feature necessitated the provision of an elaborate supervisory and monitoring system, and the installation of a complete range of standby equipment in all the signal and power circuits of the stations. The frequencies used for transmission in one direction between London and Birmingham alternate at the successive repeater stations between 917 and 937 Mc./s., and the corresponding frequencies used in the other direction are 870 and $890 \mathrm{Mc} / \mathrm{s}$. The aerial system for either transmitter or receiver consists of a dipole with a passive reflector mounted in the aperture of a paraboloidal mirror, $14 \mathrm{ft}$. in diameter. The gain of such a system is $27.5 \mathrm{db}$. over a halfwave dipole, and it is shown in the paper that a transmitter power of $6 \mathrm{~W}$. provides a satisfactory signal/noise ratio over the longest links, two of which are slightly less than forty miles. The terminal equip. ments and their associated circuits were designed to pass television signals over a band $3 \mathrm{Mc}$./s. wide, with very uniform characteristics of attenuation and phase over this frequency range, while the build-up time of the signal and the overshoot beyond the steady-state response were both required to be very small.

For some time after the opening of the Sutton Coldfield Station in December 1949, this radio link was used for programme transmission between London and Birmingham, and valuable experience was gained on its reliability and operational charac- teristics. The faults that occurred in a total operating time of four thousand hours arose mainly from electricity-supply failures, from the complexity of the control and monitoring systems, and from the accidental operation of certain keys. From the lessons which are being learned from the installation under service conditions, it seems likely that some simplification of control and monitoring facilities could be introduced into future link-systems for television and telephony.

Reverting to the more recent paper describing the complementary system of connecting by cable the London and Birmingham television stations, the authors explain that the design of the system was largely influenced by the report of the Hankey Committee published in 1945, wilich looked forward to the time when provision might be necessary for the transmission of very-high-definition colour pictures. Accordingly, it was decided to design the system so that, although initially the limit of the vision. frequency band to be transmitted would be $3 \mathrm{Mc} . / \mathrm{s}$., the system could be adapted to a much greater band width without difficulty. The cable route is about 140 miles in length, including the connexions between Alexandra Palace and Sutton Coldfield to the appropriate Post Office exchanges in London and Birmingham, respectively. Provision has been made for repeater stations at approximately three-mile intervals along the route, although at present, with the limited band-width requirement already explained, it has sufficed to equip and use only one in four of these, at a maximum spacing of less than twelve miles.

The vision-frequency signals modulate a carrier of $6.12 \mathrm{Mc} . \mathrm{s}$. at the sending-end, the lower side-band, the carrier and part of the upper side-band being transmitted over the cable. The transmission paths are provided by a pair of coaxial cables approximately one inch in diameter, and, with the repeaters at approximately twelve-mile intervals, the gain and phase delay are substantially constant from 3 to $7 \mathrm{Mc}$./s. In the event of repeater failure, change-over from working to standby equipment is effected automatically, and power for some of the intermediate repeater stations is supplied over the coaxial cables themselves. The main cable contains four other coaxial cables for telephone channels, and a number of others of the balanced-pair type, several of which are used for supervisory functions. The overall vision-frequency characteristics of the Alexandra Palace to Sutton Coldfield connexion show a total variation in gain of $0.8 \mathrm{db}$, and in phase delay of $0.04 \mu \mathrm{sec}$. for frequencies up to $3 \mathrm{Mc}$./s. Above this frequency the eut-off is rapid. The performance in respect of linearity, signal/noise ratio and time response is adequate, a fact which is supported by the reproduction in the paper of photographs showing a television test pattern before and after transmission from Alexandra Palace to Birmingham and back, that is, over twice the length of cable normally used in the exchange of programmes between these stations.

It is becoming clcar that, in the development of television and telephone systems, large national networks are likely to use both radio links and cables in a mixed cascade arrangement. This association of a trunk radio link with a cable installation in Great Britain will provide valuable experience towards the future planning and development of national and international networks in which both the radio and cable systems will play their appropriate parts. 